\title{
Proposed Expansion of the
}

\section{Library of Congress Catalog-Books: Autbors Into a Current National Union Catalog, 1956}

The following four papers were presented at the meeting of the ALA Resources Board, Philadelphia, Pa., July 4, 1955. Dr. Frederick H. Wagman, University of Michigan Library, presided.

BY CHARLES W. DAVID

\section{Background and Significance of the Proposal}

Dr. David is director of a new research library for the Longwood Foundation, E. I. duPont de Nemours and Company.

A T the Annual Conference of the American Library Association which was held in Los Angeles in the early summer of 1953, I appeared before an open meeting of the Board on Resources and presented a paper on "The Reproduction of the National Union Catalog." 1 I was then working as the chairman of a subcommittee of the Board on Resources which had had this matter under consideration for many months, had held a number of meetings on the subject, and had tormented the Library of Congress with repeated requests for study and experimentation in an effort to find a way to bring about the publication in good readable form of our great national bibliographical instrument, so that it could be made generally available on the shelves of our research libraries.

I mention these things in order to indicate that I may perhaps claim to be something of a veteran in the campaign to provide research libraries with a convenient, readily usable copy of our National Union Catalog.

But to confess the truth, the Los Angeles

\footnotetext{
1 College and Research Libraries, XV (1954), 20-26.
}

paper was no outstanding success, though it did, I think, set forth simply and honestly the record of a considerable effort directed towards a very desirable objective, which ended in failure. There were several good reasons for the failure. Due, among other things, to the refusal of Congress to provide adequate sustenance, the existing Union Catalog was not fit to be published without a gigantic effort of filing, retyping, and editing. Also there were strong reasons against publishing until a great and expensive further effort had been made to bring the catalog more nearly to completion; and the evidence which has accumulated since then has certainly confirmed this view. Finally, with the magnitude of the enterprise and with the rising costs of all bibliographical work and of publishing, we found our estimates of the total necessary outlay rising to between four and a half and five million dollars; and nobody had the courage to contemplate the possibility of any such burden as that being borne, even cooperatively and collectively, by our research libraries.

Yet in spite of the discouragement of such figures, I said in a final paragraph, "Experienced librarians will hardly be willing to write finis upon this project and condemn it to the musty files of the forgotten." Rather I suggested that the work of the subcommittee "should not ... be regarded 
as having recorded a failure, but rather as having established a bench-mark for the guidance of more successful explorers and surveyors of a later time." Today we are met to take fresh encouragement from the fact that the effort which culminated in 1953 did not end in final defeat and to take account of the fact that substantial progress has been made, particularly along one line of attack.

I have not made the necessary effort to determine just where and when and by whom the proposal was first made that the Library of Congress Catalog-Books: $\mathrm{Au}$ thors be expanded into a current national union catalog. The Books: Authors Catalog itself stems from the earlier massive Catalog of Books Represented by Library of Congress Printed Cards, which was promoted and sponsored by the Association of Research Libraries. In the course of the investigation and the discussions which led the Library of Congress to the decision in 1946 to publish its catalog currently and cumulatively in the form which has now come to be called the Books: Authors Catalog, the possibility of a later expansion of this instrument into a national union catalog was repeatedly considered and came to be regarded as an important desideratum. It was discussed at some length in a paper by C. Sumner Spalding which was read at the same meeting of the Board on Resources in Los Angeles to which reference has already been made. But I think it was not until somewhat later than this that research librarians began to be conscious of the effects which such an expansion of the Books: Authors Catalog might have on the Union Catalog problem as a whole.

If it should prove to be feasible financially and practically to expand the Books: Author Catalog into a really successful current national union catalog - with proper editing, without any cumbersome backlog of unfiled entries, without any undue delays in reporting-then would not a great burden be lifted off the existing National Union Catalog staff? Would it not then be possible to cease filing current cards into the existing catalog, as of a given "cut-off" date, thus bringing to an end (or nearly to an end) its seemingly endless expansion? If such should prove to be the case, then might there not be an end of the serious budgetary inadequacy of the Union Catalog Division at the Library of Congress, and might not the staff find itself in a position to devote its resources and its time and energy much more largely to the work of filing the back$\log$ of accumulated cards, to editing and retyping unsatisfactory cards, and perhaps most important of all, to bringing the catalog more nearly to completion. Thus would some of the obstacles to publication which have been noted above gradually be removed -with the hoped-for result that the catalog might ultimately be published and made widely available. Such reasoning had a very strong two-fold appeal. First, it offered the almost immediate hope of a published current national union catalog, which within a few years would inevitably grow into something retrospectively important. Second, it offered the hope of lifting a great burden of frustration from the shouders of the existing Union Catalog staff and of preparing the way for the ultimate publication of that great bibliographical instrument.

So far as I am aware, this line of reasoning was first developed in an informal conversation late one evening in a hotel lobby in Minneapolis during the ALA Annual Conference a year ago. It was further discussed and developed in a meeting of the Board on Resources a day or two later; and since then it has been under active consideration by a new subcommittee of the board, of which Frederick $\mathrm{H}$. Wagman is chairman, by the Library of Congress, and by the board itself.

The subcommittee held long meetings at the Library of Congress in October of 1954 and in January of the present year, and it has laid on the Library of Congress a tremendous burden of investigation, calculation, and planning. At the January meeting of the subcommittee the Library of Congress presented detailed studies of alternative plans, together with some 32 pages of statistical tables showing the probable number of cards to be handled and giving estimates of subscription costs. After these difficult data had been examined with as much understanding as the members of the subcommittee could bring to bear upon them, the general outline of the plan which is today before us was unanimously approved. Since 
then the plan has been studied further by the Library of Congress and by the Board of Resources; it has been formally approved in principle by the board and by the Association of Research Libraries, and it has been laid before many librarians here present in writing, together with a request that they indicate their willingness to have the institutions which they serve subscribe to a considerable number of copies of the expanded catalog, thus offering the assurance of financial feasibility.

The plan itself, together with reasons for its adoption, will be presented to you in some detail in the following paper by the chief of the Union Catalog Division of the Library of Congress. The remainder of my assignment is to express my convictions about the significance of the proposed expanded catalog.

Here I think I had better begin by making the honest confession that I am an avowed advocate of this project rather than an impartial judge. It is true that I have had to learn some degree of moderation since in my first enthusiasm over the possibilities of modern reproduction techniques I shared, a good many years ago, in the authorship of an article which seriously proposed the compilation of a world thesaurus; ${ }^{2}$ but I still hold with deep conviction to the view that American scholarship, American librarianship, and the national interest require that we have in our research libraries a welledited, conveniently usable, national union catalog which will reveal, with locations, substantially our total national library resources. The efforts which have been made in recent years, mainly under the sponsorship of the Board on Resources, have seemed to demonstrate that such a union catalog, however desirable, is not presently a practical possibility. But the more limited project which is before us today does seem to me to be eminently practical and possible and to constitute a great forward step in the right direction.

The Library of Congress Catalog-Books: Authors when first proposed was, I think, viewed by a good many librarians with real misgivings, but it has succeeded beyond expectations and has now come to be regarded

\footnotetext{
2 "A Cumulative World Thesaurus," The Journal of Documentation, III, (1947), 43-45.
}

as an indispensable tool in both the technical and the service divisions of a great many libraries, even fairly small ones. I am convinced that the proposed expanded cata$\log$, because of its greater riches, will prove to be even more indispensable in pretty nearly all the connections in which the present Books: Authors Catalog is used.

Moreover, as in the case of the present Books: Authors Catalog, currency, especially because of the regular and systematic cumulations, soon stretches out into the long range, and so it will be with the proposed expanded catalog.

The statistics of the experience of union catalogs on cards, both national and regional, on which I would like to lay hands at this moment appear for the most part not to be available; but the Union Catalog Division of the Library of Congress has been able to provide me with partial data which seem to me to be worthy of attention. Leaving out of account the unrecorded searches of individual scholars who visited the Union Catalog and used it personally, it appears that during the first quarter of 1954 a total of 3,293 requests for monographs were received and searched by the Union Catalog. Of these $13.5 \%$ bore imprint dates of the 15-year period 1940 through 1954; $23.5 \%$, imprint dates of the 20-year period 1920 through 1939; and $11.5 \%$, imprint dates of the 20-year period 1900 through 1919. The total for the 55 years 1900 through 1954 was therefore $48.5 \%$. The staff of the Union Catalog Division believes that these statistics, though obviously pretty limited and taking no account of the inquiries of individual searchers outside the Union Catalog staff, are nevertheless fairly representative. The broad conclusion would therefore seem to be that about one-half of the inquiries made at the Union Catalog in Washington are for items published during this present century.

I think it is fair to observe, however, that the kind of inquiries which one commonly takes the trouble to send or carry to Washington are likely to be the difficult ones for items bearing the older imprint dates. If we had a satisfactory published union catalog conveniently on our shelves, I am convinced that the use of it would be for the searching of recent imprints much more largely than 
the Washington experience examined above would lead one to expect. This view is confirmed by the staff of the Philadelphia Regional Union Catalogue. While they have not compiled statistics on this point, it is their unanimous impression that the inquiries with which they have to deal are much more preponderantly for imprints of relatively recent date. To me it seems probable that the Philadelphia experience is a better indicator than that of Washington as to what we might expect as to the use of the proposed expanded Books: Authors Catalog. I believe in short that, if the proposed new venture succeeds, most of us will be astonished at the rapidity with which our new tool takes on great retrospective importance and provides convenient answers to a great number of our questions.

And as for the existing National Union Catalog on cards, which will, I am convinced, be greatly assisted by the launching of the proposed new current catalog, we are not yet in despair of ultimate publication, as I hope other speakers on this program will presently convince us.

Speaking now from the viewpoint of a large university or research library, what claims can I properly make for the importance and the usefulness of the proposed expansion of the Books: Authors Catalog into a current, cumulative national union cata$\log$ : In order to clarify my thinking on this subject, I have conferred about the project with a good many of the members of my staff whose experience should lend weight to their judgment. Their comments have been unanimously favorable. In the acquisitions department $I$ have been assured that the expanded catalog would be of great assistance to the searchers in their effort to establish correct entries and to the department as a whole in its effort to form an idea of the contents of a proposed purchase and so reach a sound decision as to whether to proceed with the purchase or not. In the cataloging department there was equal enthusiasm. It was felt that the new tool would be of much value in establishing author identity for both current and non-current material, that it would greatly lighten the burden of searching, and that it would be of much help in dealing with the difficult subject of corporate headings. We have in our library an important enterprise of cata$\log$ revision which stems from the bad practices of former generations. Here again I received assurance from the catalog reviser that the new instrument would be of much assistance, particularly because of the record it would supply of the practices of other institutions. The reference department was equally emphatic. It was particularly noted that the expanded catalog would supply much bibliographical information on authors which is elsewhere far more difficult to come by, that it would be of great assistance in the handling of the growing traffic in interlibrary loans, and that it would constitute a reference tool of great importance not only for librarians but for the faculty and students which we serve.

On reflection I wonder why I have taken the trouble to make these inquiries among the members of my staff. American librarianship has been firmly committed to the concept and to the cooperative support of the union catalog idea for several decades. Resolutions calling for the "completion" of the National Union Catalog have been numerous and they have been unchallenged. More recently the demand has been growing for the National Union Catalog not only to be "completed" but to be properly edited and legibly published for wide distribution and use. The proposed expansion of the Books: Authors Catalog into a current cumulative union catalog will certainly not wholly meet these demands, but my own conviction is that it will constitute so great a forward step towards the desired goal that it ought hardly to be necessary to argue the case in its favor, provided a plan can be devised which offers good hope of its being financially self-supporting. And here I would also point out that past experience with such cooperative enterprises seems to indicate that once they have been got under way our capacity to sustain them is likely to be greater than was at first thought possible.

Lest what I have so far said should seem to some of you an unblushing piece of promotion, let me add a final word of caution. I will not claim that the plan as now formulated and about to be laid before you is beyond criticism or that it will give us truly the current union catalog of our dreams. There will inevitably be blemishes and in- 
consistencies in it. There may be difficulties about prompt reporting and editing. More serious, as it seems to me, may be the inadequacy of the reporting by cooperating libraries across the country. In the initial stages I am convinced that the catalog's coverage of our total resources and its representation of their geographical distribution will be inadequate. But here I believe that there is need for an act of courage and faith. Just as in the matter of financing, so here in the matter of coverage and geographical distribution, if we can get the enterprise under way, I believe that improvements can be made and the blemishes be removed as we go forward.

By GEORGE A. SCHWEGMANN, JR. and ROBERT D. STEVENS

\section{The Proposal for a Current Author Catalog of}

\section{American Library Resources}

Mr. Schwegmann is chief and Mr. Stevens is assistant chief of the Union Catalog Division, Library of Congress.

$A^{s}$ 5 YOU HAVE HEARD from the preceding speaker, the proposal of the ALA Board on Resources that the Library of Congress Catalog-Books: Authors be expanded to include the catalog entries of other libraries for 1956 and later imprints is the fruition of several decades of serious consideration of the problem of providing librarians and scholars with a printed and widely distributed record of current American library resources and represents the first concrete step toward publication of the National Union Catalog in book form. Because of the extreme importance of such a published record, the Library of Congress welcomed the suggestion of the board that a questionnaire be sent to all present subscribers to Books: Authors asking if they would continue their subscriptions to the Catalog if the recommended change in scope, which would entail an increase in subscription price, was adopted.

The recommendation of the board was made on February 1, 1955. On April 18, 1955 , letters describing the project and questionnaires were sent to 650 subscribers. By June 15 responses were received from 515 subscribers indicating that they would subscribe to a minimum of 700 copies.

\section{The Responses to the Questionnaire}

The promptness of answer and the high percentage of responses to the questionnaire were convincing evidence of the widespread interest in this proposal. Although the questionnaire did not specifically provide for comments, many of the 451 librarians who answered in the affirmative took the opportunity to praise this step. In this group of affirmative answers, 421 librarians indicated they would continue their subscriptions at the present level, and 30 were enthusiastic enough about this cooperative venture to indicate that they would subscribe to extra copies if necessary to assure its financial success. Some of the 64 respondents who indicated that they would cancel or decrease the number of their subscriptions also commented on the proposal. In the main the adverse comments fall into three categories: (l) an objection to the increase in price in view of a limited budget for the purchase of books; (2) the opinion that cards other than Library of Congress printed cards would be of no use to the particular library; and (3) a fear that the increased size of the catalog would result in a slowed-down publication schedule. On this last point we hasten to reassure you. The increase in size of the catalog will not change the editorial deadlines nor will it mean that the issues once edited will be any longer at the printers than at present. 
In summary, $75 \%$ of the present subscribers to the Library of Congress Catalog have responded to the questionnaire and nearly $90 \%$ of the responses have been favorable.

\section{Historical Background}

Dr. David's résumé of the previous discussions and proposals makes it clear that prior to last fall when the presently constituted Committee on the Union Catalog of the ALA Board on Resources first met, all aspects of the problem of publication of the National Union Catalog had been thoroughly discussed and all that was lacking was a catalytic agent to prompt action. The catalytic element introduced late in 1954 was the concept that a start toward solving the problem of publication of the National Union Catalog might best be made by first publishing a current supplement to a projected main work which could be published when feasible in the future. This is not to say that no thought had previously been given to the possibility of expanding the Library of Congress Catalog by the inclusion of catalog cards prepared by other libraries, for, as many present will remember, this possibility was discussed by C. Sumner Spalding at an open meeting of the ALA Board on Resources on June 25, 1953.1 It was in October 1954, however, that Dr. Frederick H. Wagman first introduced the concept that publication in the Library of Congress Cata$\log$ of all information about current imprints would relieve the staff of the $\mathrm{Na}$ tional Union Catalog of the considerable burden of arranging, filing, maintaining, and answering reference queries about current books. In effect, Dr. Wagman pointed out, relief from these duties would gradually increase the proportion of the staff of the National Union Catalog left free to concentrate on the problems of completing, editing, and preparing for eventual publication of the National Union Catalog record of holdings of books published prior to 1956 and at the same time would make available a reference tool for current imprints of considerable immediate value.

It is expected that this step will relieve

1 C. Sumner Spalding, "Library of Congress Book Catalogs: Proposed Expansion into Current Author Catalogs: Proposed Expansion into Current Author and Subject Catalogs of American Library Resources,
College AND RESEARCH LI BRARIES, XV (1954), 15-22. the pressure on the staff of the Union Cata$\log$ Division in two ways: first, on the basis of detailed statistical studies it can be predicted that by 1958 the division will find its arranging and filing operations reduced by at least 200,000 cards per year or by onethird of the present work load; second, it is anticipated that publication of location information about current imprints will lighten the burden of searching since samplings of requests to the division have indicated that as high as $20 \%$ of the searching load is for imprints of the past ten years. Provided the staff of the Union Catalog Division can be maintained at its present level, relief from these duties should leave available man-hours urgently needed for the completion and editing of the older portion of the National Union Catalog.

The first step which led to the present proposal was taken on October 20, 1954, when the ALA Board on Resources Committee on the Union Catalog, having reviewed its previous decision not to recommend publication of the National Union Catalog in microcard or microprint form, requested the Library of Congress to provide it with detailed information concerning the cost of preparing and publishing a Current Author Catalog of American Library Resources.

The Union Catalog Division possessed basic data in the form of statistics of receipts of cards for current imprints since 1952. The effort of translating these statistics into estimates of cost for publishing current imprints in alternative formats required several hundred hours of staff time of members of the Processing Department. By the time of the next meeting of the Committee on January 14, 1955, the staff of the Library of Congress had prepared and distributed to the committee members a working paper ${ }^{2}$ consisting of 24 pages of text and 32 pages of statistical tables.

After the committee's meeting of January 14,1955 , a summary of the decisions taken to date was sent for information to members of the Board on Resources and to all mem-

2 The working paper bore the heading "ALA Board on Resources Committee on the National Union Catalog Proposal to Expand the L.C. Author. Catalog [sic!] to Include Union Catalog Cards for Entries for 1952 and Post-1952 Imprints. December 27, 1954." 
bers of the Association of Research Libraries. ${ }^{3}$

\section{The Alternative Proposals Considered}

Once the decision had been reached that a book catalog printed by conventional photo-offset techniques would provide the most usable form of publication and with the committee unanimously agreed that the most feasible approach to the matter would be to concentrate on the problem of current additions to the National Union Cata$\log$, it remained only to identify, define, and compare alternatives as to the beginning imprint date of works to be represented, pattern of issuance, and types of materials to be included. With the working paper in hand the committee was able to base its ultimate recommendations on factors both of usefulness and cost to the consumer.

The years from 1952 through 1956 were considered as alternative beginning imprint dates for works to be represented in the Catalog. The idea of using 1952 as the beginning imprint date was considered simply because it was in that year that the Union Catalog Division had started to segregate and file separately cards for current imprints as they were received. Serious consideration was given to beginning with 1953 imprints on the ground that use of this year as a cutoff date would have made the 1953-1957 quinquennial cumulation of Books: Authors a complete, published union catalog for current imprints cataloged during the period. The difficulty with either of these dates was financial since, if 1953 were used there would have been an estimated 440,000 main entries, added entries, and cross references to be edited, retyped, and printed during 1956 and 1957. The cost of preparing these entries accumulated over a period of five years would have had to be met from the 1956 and 1957 subscription fees which would have come to $\$ 350$ per year for each of the two years. Under normal circumstances, of course, the cost of preparing entries for any five-year period will be spread over the subscription fees for the entire five years. These same considerations of cost applied, though

3 "Proposal to Expand the Library of Congress Catalog-Books: Authors to Include National Union Catalog Cards Representing Imprints of 1956 and Later," with accompan
1955. 2 pp. processed. in lesser degree, to any of the years between 1953 and 1956. On the basis of these cost figures the committee concluded that it would be best to get a fresh start in 1956 with the cataloging reports for current imprints. The use of 1956 as a beginning imprint date as finally decided will mean that approximately 112,000 entries from sources other than Library of Congress printed cards and an estimated 64,000 reports of additional locations will be prepared and published during the biennium. The cost under this proposal will amount to $\$ 170$ per year for each subscription during 1956 and 1957.

The question of pattern of publication, that is, of frequency of issue, of frequency of cumulation, and of whether entries from all libraries would be included in all issues, was also decided on the basis of cost and convenience to the users. Basically, it was decided that it will be essential to retain the present pattern of publication and cumulation so far as the Library of Congress portion of the catalog is concerned on the grounds that subscribers have come to depend on monthly issues for speed in securing cataloging and card ordering information and on frequent cumulations for convenience of use. The question then remained of whether cards and reports of holdings from libraries other than the Library of Congress would be included in all issues or only in the larger cumulations.

Six alternative patterns of publication were discussed and evaluated. The first plan discussed was that of adding entries and reports of holdings from libraries other than the Library of Congress only to the annual and quinquennial cumulations and omitting them entirely from the monthly and quarterly issues. The savings under this plan would have been in printing costs only since it will be necessary to prepare and edit copy furnished by other libraries for inclusion in the annual volumes. These potential savings of printing costs would have amounted to a maximum of $\$ 15$ per subscription.

The second plan considered and that finally adopted was to continue the present pattern of publication of Library of Congress entries and to add to all issues cards from other libraries, representing works published in 1956 and later as they are received 
by the National Union Catalog. Under this plan the pattern of issuance and contents of the issues of the catalog will be as follows:

1. Monthly issues: Library of Congress printed cards and National Union Catalog cards for the current and past two imprint years. (In 1956 and 1957 the National Union Catalog cards will be for only 1956 and 1957 imprints but in 1960, for example, the monthly issues will contain Union Catalog cards for 1958, 1959, and 1960 imprints.)

2. Quarterly, annual, and quinquennial issues: Library of Congress printed cards for all imprint dates and National Union Catalog cards for imprints of 1956 and later.

3. Locations of additional copies will be shown in all issues, but main entries will not be reprinted outside of the normal pattern of cumulation simply to show reports of holdings received since publication of the entry. If a main entry had appeared in the January-March quarterly cumulation, reports of additional locations received in April and May or later would be held for printing when the appropriate main entry is next cumulated in the annual volume.

The estimated cost of individual annual subscriptions under this plan is $\$ 170$ during 1956 and 1957 and $\$ 245$ annually in later years.

The third plan contemplated dropping Library of Congress cards for imprints earlier than 1956 from the monthly, quarterly, and annual issues and including Library of Congress cards for all imprints only in the quinquennial cumulations. This plan would have reduced the annual subscription by $\$ 25$ but would have seriously impaired the usefulness of the catalog. Plans 4, 5, and 6 represented less acceptable variations of Plan 2 and need not be discussed in detail. The individual annual subscription costs during 1956 and 1957 under any of the plans considered would have been in the narrow range of $\$ 145-\$ 175$.

Under the plan of publication adopted, Library of Congress main entries, added entries, and cross references will be included at approximately the present rate of
120,000 per year while similar entries from other libraries will be included at the rate of 31,000 during the first year and increased to 130,000 or more entries per year during the 1960 's.

The estimates of the number of cards for imprints of 1956 and later to be received by the National Union Catalog over the next decade and a half are based on a strict accounting of the cards received for 1952 and later imprints and on extensive samplings of current receipts of cards representing earlier imprints. These figures formed the basis for all estimates of cost; they are as accurate as we can make them, but they are subject to change as the size of cataloging staffs, cataloging policies, or acquisitions policies of the contributing libraries may change. We venture to predict that the publication of cards from other libraries may encourage additional libraries to contribute, which in turn would lead to an upward revision of the present estimates.

Other lesser decisions as to scope of the catalog concerned a number of types of materials. For the present, entries for serial publications will be included-this will represent some duplication with New Serial Titles, but it should be remembered that these will be full cataloging entries and not the abbreviated accessions list type of entry found in New Serial Titles. Entries in nonRoman alphabets, except those on Library of Congress printed cards, will not be included because of technical difficulties of transliteration or reproduction. Such entries in the non-Roman alphabets as are received by the National Union Catalog will be sent as heretofore to the special language union catalogs in the Library of Congress for retention and possible later publication. In the case of the Cyrillic alphabet material there is the possibility that there will be a published union catalog sometime in 1956 with the Monthly List of Russian Accessions serving as a kind of supplement.

The problem of what limitations should be placed on the number of locations reported for any one item is a thorny one for which only a temporary solution has been reached. The present plan is to publish all reports of locations received except those for United States government publications distributed to depository libraries, for United 
Nations publications which are also widely held by depositories, and for the publications of the states of the United States which may normally be found in the respective state libraries. The question of how many locations should be shown for commonplace books in the American book trade has not yet been fully answered, but we would do well at this time to take steps to assure that adequate reporting is obtained from all regions of the United States. This is a question on which advice and help from the library profession at large will be needed. David and Hirsch, in a recent article 4 in Library Trends, pointed out present deficiencies in the National Union Catalog record of book holdings in several regions, but in connection with any attempt to assure full regional coverage the cost of handling the increased number of reports must always be kept in mind.

The editorial policy to be applied to the entries supplied by other libraries may be stated briefly. Wherever a Library of Congress printed card is available it will be used. If an entry is first furnished by another library and a Library of Congress printed card becomes available the Library of Congress card will be substituted in the next issue of the Catalog. If the entry is not the same a cross reference will be provided. Entries from other libraries will be searched in the Library of Congress official catalog and edited for consistency in form of main and added entries. All other information on the card will be printed in the catalog as supplied by the contributing library. No decision as to the inclusion of class and book numbers supplied by other libraries has yet been reached.

The entries from other libraries will be retyped on Coxhead composing machines or other copying equipment in a type face and format similar to that of Library of Congress printed cards. As a result, except for the addition of location symbols, the printed catalog will have the same typographical appearance as the present Books: Authors.

The Basis for Pricing the Current Author Catalog of American Library Resources

The task of estimating the cost of the

${ }^{4}$ Charles W. David and Rudolf Hirsch, "Coopera. tion and Planning from the Regional Viewpoint," tion and Planning from the Region
Library Trends, III (1955), 356-375. expanded catalog was tedious but clear-cut enough once the policy decisions mentioned above had been made. The operations necessary to the receipt, segregation, checking, filing, editing, and preparation of copy for printing were listed step by step in minute detail. The number of man-hours necessary to accomplish the operations was determined by applying the production rates obtaining for similar tasks now performed in the various divisions of the Processing Department of the Library of Congress. With these figures in hand it was possible to arrive at staffing requirements. Estimates of the proper pay grades and salaries were based on those for comparable positions in the $\mathbf{L i}$ brary of Congress. Figures on printing costs were based on those for the present Library of Congress Catalog for which we have statistics going back to 1948 on the average number of entries per page and the actual charges for the printing and binding of the monthly, quarterly, and annual issues. The above cost estimates were totaled and the amount of $10 \%$ was added as required by the Act of June 28, 1902, which makes it mandatory that card indexes and the other publications of the Library of Congress be sold at cost plus $10 \%$. The annual subscription rate during each five-year period was then arrived at by averaging annual costs for the period and dividing by the anticipated number of subscribers. Since 1956 and 1957 are the last two years of a quinquennial period the total costs for these two years were averaged at the rate of $\$ 170$. Similarly, the rate of $\$ 245$ per year was established for subscriptions after 1957. The projected subscription rates were worked out as carefully as possible and we feel that these estimated subscription rates will stand up unless further affected by variables over which we have no control, such as increased salary and printing costs or a considerable increase in the number of entries sent by contributing libraries.

Several of the respondents to the questionnaire have asked if there would be a reduction in price for copies beyond the first purchased by any single subscriber as at present. Other libraries have asked why a service basis for subscription charges would not be possible. Aside from the fact that we do not believe that the Library of Congress 
could legally sell this catalog on a service basis, the plain facts are that a service basis charge is to the advantage of the smaller libraries while the larger libraries would prefer to see a reduction in charge for copies beyond the first. The present decision of the Library of Congress to charge the same price for additional subscriptions results from the fact that we are not aware of any feasible alternative which would provide the necessary funds and it actually tends to favor the smaller libraries which take only one copy because under the proposed price schedule those libraries which subscribe to multiple copies will bear an increased proportion of the cost. For example, a large library now paying $\$ 200$ for three subscriptions to all issues of Books: Authors will pay $\$ 510$ for three copies of the new catalog. This is a $150 \%$ increase in cost as opposed to the $70 \%$ increase in cost to the smaller institution subscribing to only a single copy. However, even at $\$ 510$ or $\$ 735$ the large library will be spending less than it would if it were to undertake to file and maintain a depository set of Library of Congress cards or a file of proof sheet entries. This pricing policy is in effect a reversal of the present policy under which the additional copies are sold at half the price of the first copy, but it will be recalled that this pricing policy was adopted only after the financial success of the Library of Congress Catalog was assured.

As to the relative benefits to be gained from the catalog by the smaller libraries, we think it safe to say that benefits will not be so much a function of size of the institution as of the imagination and resourcefulness of the librarians who will use this tool. The price of a single subscription which amounts to only 47 cents a day during the first two years and to 67 cents per day thereafter is a small price indeed to pay for the most comprehensive bibliographical service that the world has ever known.

\section{The Implications of the Publication of the Current Author Catalog of American Library Resources}

We are convinced, as are the members of the committee, that the decision at this time to publish the proposed expanded catalog beginning in January 1956 is comparable in importance to the decision that was made in 1901 to distribute Library of Congress printed catalog cards on a wide basis. Just as the 1901 decision widened the horizons of American librarianship by making readily available in many locations through depository catalogs and otherwise information about the resources of a single great library, the present decision will broaden horizons by disseminating information about the resources of the major libraries of North America. The full potentialities of this new catalog remain to be discovered and exploited. The most we can do now is to predict that the availability of this tool will radically change some of the traditional patterns of American librarianship. In the field of interlibrary lending we may expect to see a shift from the present burden on a few of the largest libraries to a more equitable distribution of the lending burden. The present trend toward borrowing closer at home, which depends now on the information furnished by regional union catalogs where they are available, will undoubtedly be intensified. Moreover, since information about the location of various works will be readily available, it seems probable that the catalog will be used more and more as the basis for the regional or national planning of acquisitions. Certainly the librarian of the future who is considering the acquisition of an expensive work will consult the printed catalog to determine whether a copy is already close at hand. The ready availability of a mass of bibliographical information should be reflected in lowered costs of acquisition, cataloging, and reference work. As a bibliographical tool the catalog will be of great value from the very beginning and as the years go on its value will steadily increase because the complete literary output of most of the authors of the latter half of the twentieth century will be brought together in it.

\section{The Need for an Advisory Committee}

The importance of the step we would take in publishing this catalog which will affect every aspect of American library economy makes it imperative that it be made as useful a tool as is possible. It is abundantly clear that there are many problems yet to be settled and that the Library of Congress 
will need a great deal of cooperation and advice in carrying out this enterprise. For this reason we are asking the Board on Resources to establish an advisory committee to aid us in reaching the decisions that must be made. The Library of Congress has found the advice of the Joint Committee on the Union List of Serials extremely helpful in its efforts to improve the publication New Serial Titles. Similarly, another committee would help us to make this current author catalog of North American library resources a work of maximum usefulness to all users.

The widespread acceptance of the proposal that we have outlined is as gratifying to the administrative officers of the Library of Congress as it is to the Committee on the Union Catalog of the ALA Board on Resources and gives us confidence to pursue the planning to commence expansion in January 1956 if the Board on Resources will recommend that we do so.

We might add, that the sentiment of the Association of Research Libraries in connection with the matters under discussion here are reflected in the text of the following two actions which were taken by the Association on January 31, 1955:

1. "That the ARL endorse in principle the proposal to expand the Library of Congress Catalog-Books: Authors."

2. "That the ARL urge the Library of Congress to proceed, after having expanded the Library of Congress Catalog, to consider the possibility of reproducing the basic Union Catalog in photo-offset form, with such re-editing and re-typing of titles as necessary."

BY HELEN M. BROWN

\section{The Proposal from the College Library Viewpoint}

\author{
Miss Brown is librarian, Wellesley Col- \\ lege.
}

$\mathrm{C}$

OLLEGE LIBRARIANS have been greatly disturbed by the treatment of the college library in the 1952 Report of the Commission on Financing Higher Education. In attempting to suggest possible economies for the admittedly financially hard-pressed institutions the report states that general agreement was found that a "good" liberal arts college ought to operate with a book collection of under 100,000 volumes, many of which would be duplicates. What has troubled the college librarians is the apparent negation of the essential differences among college libraries shaped as they are by the programs of their parent institutions. The recognition of these differences is pertinent to this discussion. Let us pose the hypothetical question, "Why should the college librarian whose budget and building needs have to compete with demands for increased faculty salaries and higher maintenance costs welcome the expansion of the L.C. author catalog into a current national union cata$\log$ costing twice as much and requiring twice as much shelf space?" I submit in answer that the degree to which the college library will welcome the expansion is in direct ratio to the degree to which it accepts a research function.

Many of you will have seen "A Plan for Meeting College Library Problems: A Report of the Regents' Committee on Integration of College and University Library Resources in New York State" or Mr. Reuben Frodin's discussion of it in the October, 1954, Library Quarterly. In considering the provision of material for faculty use the report makes the point that special material of value in faculty teaching acquired by the college library "plays back" into the quality of the teaching and should be bought as freely as possible. In regard to material used by faculty members in research which is less directly related to their teaching the report suggests it should be bought when the prospects of its continued usefulness seem to merit the expenditure. This criterion of potential use 
is the one which most of us employ in deciding what shall be purchased for faculty research outside the field of any special collections which our libraries may be developing. Beyond this our responsibility for faculty research lies in the area of maintaining the best bibliographic equipment possible and aiding the faculty member to secure the desired material through interlibrary loan, microfilms or other reproductions or by introduction to a research library owning the items.

The library with this view of its responsibility to faculty research will find the proposed union catalog of increasingly greater value as the years pass. The editing of nonL.C. entries for conformity of main entry, the provision of adequate cross references and the noting at the bottom of the entry of appropriate added entries, both author and subject, will increase the usefulness of this already indispensable cataloging tool. In the area of cataloging the actual return to the individual college library from the expansion will necessarily be conditioned by the amount of material the library acquires in the non-L.C. category. Of the greatest value to more college libraries will be the use of the National Union Catalog as a reference tool for the verification and location of titles to be requested on interlibrary loan. Ultimately the catalog will provide a series of comprehensive author bibliographies describing and locating the material. These uses of the National Union Catalog for college faculty research will not differ in kind from such use in the university library.

Equally important to the college library is the possible contribution of the expanded catalog to its services to the undergraduate student. I am now speaking from the viewpoint of a college (and there are many such in the country) with a scholarly faculty, a student body limited in number so that it has become highly selective, a moderate teaching load and a history of good library support-all factors leading to the generous use of the individual study project as a method of teaching. Since the faculty member usually demands that the major part of the project be based upon original sources, this undergraduate work provides the student with an initial experience in research -a foundation for the comparatively few who will go into scholarly careers; the sole experience of the many. It is manifestly the responsibility of the college library to provide the basic material for such special studies and honors work, seeking only to borrow additional materials which will be of little future use in the library. In many of our college libraries, therefore, will be found important collections of sources in the fields represented in the curriculum and a student may, in the course of writing a paper on Bishop Grossteste, use the Historia Anglorum of Matthew Paris as reprinted in the Rolls Series or make a study of eighteenthcentury literary criticism in the files of the Gentleman's Magazine.

The layman might suppose that in college libraries of this kind the number of requests for material not in the library's own collection would be fewer than in other college libraries. To the contrary, in the course of using the bibliographical tools in the field of his major interest, the student frequently comes across titles which seem important to his purpose and are not available in the home library. The student's satisfaction in his academic work demands that the library meet his need. We at Wellesley College handle many such student requests, meeting some by borrowing titles on interlibrary loan or by sending the student with a letter of introduction to another library. (It has not been statistically determined how many of our students take advantage of the great research library in nearby Cambridge, not under the auspices of the library but through friendship with a Harvard undergraduate.) It is my guess that ultimately the National Union Catalog, because it will be easy to use and will locate copies, will remove a psychological barrier between the student and the book and will result in increased undergraduate demands for material in other libraries. I think this will be especially true in fields such as literary studies in which the author approach is so important.

I further prophesy that the increased undergraduate student demand for material outside the home college library will serve to intensify two trends now present in college-university relationships. The first of these is the growing reluctance of the university libraries for good and sufficient rea- 
sons to meet any and all requests for interlibrary loans from neighboring colleges. Some of these larger institutions in self defense have had recourse to limiting the number of loans to one college or have required the payment of a nominal fee for library use by outsiders. Neither of these particular solutions is desirable from the standpoint of the borrowing library for while the individual undergraduate student's need for material outside his own library collection is apt to be limited in time to a few weeks and in scope to one or a few volumes, the total number of such requests is apt to snowball at times of academic pressure. I believe that as the National Union Catalog becomes a more and more effective interlibrary loan tool, it will become necessary to regularize the relations between the libraries of colleges and nearby universities, perhaps along the lines of contractual agreements.

The second trend which I expect to see intensified as the Union Catalog increases in years is that toward cooperation among the colleges themselves. The outstanding example of the Hampshire Inter-Library Center has been possible, of course, because of the close geographical location of colleges with a like academic atmosphere. I know personally of another attempt by several more scattered colleges to form a kind of interlibrary loan union which died a-borning because of the obvious difficulty of locating materials within the group quickly enough. The National Union Catalog will at least put into our hands a tool for locating materials held among colleges which by reason of near location or some institutional association have a reasonable claim upon one another.

The creation of such agreements poses weighty problems of program analysis and organization. If they can be satisfactorily effected, however, the next step would be to use the National Union Catalog as a tool for cooperative acquisition programs. In my opinion the proposed expansion of the L.C. author catalog has almost incalculable significance for the college library.

\section{By KEYES D. METCALF and ANDREW D. OSBORN}

\section{Proposal for Publishing the National Union Catalog}

Dr. Metcalf is professor, Graduate School of Library Service, Rutgers University; Dr. Osborn is assistant librarian, Harvard University Library.

$\mathbf{M}^{\prime \prime}$

ANY OF THE most important decisions reached by librarians must be made on an appraisal of relative values. As a rule we must make a choice, not between good and bad, or black and white, but between ways by which we can obtain the best returns from the limited funds available. This observation is, I think, a commonplace in day-to-day administration. It applies also to related library enterprises, a good example of which is one that is not very different from the problem under consideration-the Union List of Serials-the first edition of which was successfully compiled and published thirty years ago.
Despite its name, the Union List of Serials did not attempt to record all serial publications; instead it concentrated on selected groups. These groups comprised what can rather loosely be called periodicals and society publications which were recognized as the serials whose listing would be most profitable to all concerned. In the compiling and editing of the Union List of Serials its editor, Winifred Gregory, aimed at the best practical results, not at a polished and definitive bibliography. With these limited aims she was able to push the work to a conclusion. Its success can be gauged by the statement of a British colleague who last year hailed the Union List of Serials as "the greatest union list ever published."

The precedent provided by the Union List of Serials may well help in the somewhat similar project, the National Union 
Catalog, which many of us have long hoped could be published, but which when considered realistically seemed almost impossible for two reasons:

First, the tremendous size and cost of the undertaking was apparently so great as to make the task impossible without a very large subsidy.

Second, there seemed to be no prospect of an adequate subsidy if the publication was to be maintained on a current basis. Experience has shown that a catalog of this kind is out of date before publication; its day of usefulness is short unless ways and means can be found for continuations or supplements; and foundations are not interested in subsidizing projects that must be continued indefinitely.

Recent events have put a new aspect on the second of these problems. It now seems likely that, beginning with January 1956, the currently published Library of Congress author catalog will include in its cumulations, and possibly in its monthly issues, a record of the more important holdings of a large group of cooperating libraries in addition to those of the Library of Congress. If this hope becomes a reality, the task of publishing the material in the National Union Catalog as it now stands has a much more definite limit and may become sufficiently manageable in size so the thought of publication should be considered afresh. A study of the situation, however, seems to indicate that even so publication of the complete National Union Catalog would still be too large a task to be undertaken as a self-supporting project, and probably too large for us to hope to have it made possible by a subsidy.

This is the point at which the precedent of the Union List of Serials comes in. It has seemed to some of us that considerable portions of the National Union Catalog might be omitted without doing serious harm just as there are many types of serial publications whose omission did not seriously impair the value of the Union List of Serials. If these portions are omitted and the editorial work is carried on along practical lines, it might well be possible to publish the National Union Catalog successfully and still include in it a very large* percentage of all the information desired by librarians and bibliog- raphers if a comparatively small subsidy were made available. Under these circumstances we should stand a better chance of securing the subsidy. With all this in mind a study has been made of groups of titles which might be considered for exclusion. A discussion of them follows.

\section{Titles in the Library of Congress Printed Catalog}

Far and away the biggest saving can come from omitting all items in the Library of Congress printed catalog. Vast numbers of Library of Congress entries represent either unique holdings or popular titles which can be found in thousands of libraries. There is little point in listing either type in the published National Union Catalog whose primary objectives are to provide titles and locations not given in the Library of Congress printed catalog. However, it must be admitted that the omission of the nonunique titles will at times conceal multiple locations which could profitably be disclosed and that there may be a somewhat heavier burden of interlibrary loan requests on the Library of Congress. But some of these requests can be passed on to other libraries through the existing records of multiple holdings at the Library of Congress.

All things considered, it seems wise to suggest that the Library of Congress printed catalog and the published National Union Catalog be considered complementary works; or, in other words, to propose that publica. tions listed in the Library of Congress printed catalog be omitted from the published National Union Catalog.

\section{Serials}

The major reason for recommending the exclusion of serials is that holdings cannot be satisfactorily given in the proposed publication, except for titles which are complete and dead. Without holdings, the listing of serials would not be satisfactory. In addition, it must be remembered that the Union List of Serials and the New Serial Titles list go a long way in caring for needs in this field. Accordingly, it seems desirable to suggest that lists of serial holdings be left for the Union List of Serials in whatever form that may take from now on, and to omit the 
serials from the published National Union Catalog.

\section{Non-Book Materials}

Although entries for non-book materials are not numerous, it will simplify compilation and editing of the published National Union Catalog if they are omitted. They include broadsides, maps (but not atlases), manuscripts, etc. Popular sheet music might be classed with the non-book materials for omission. Microreproductions of books and pamphlets might be included, except when these are part of a large-scale publication program such as the English short-title list and Evans, for example.

\section{Early Printings}

Incunabula do not need to be included, since they are covered by the Stillwell census. Likewise, early British imprints can be left to the Short Title Catalogue and Wing, and early American titles to the American Antiquarian Society project to reproduce on microprint cards American publications before 1801 .

\section{Offprints and Paged Analyticals}

Although periodical articles are not infrequently requested as though they were books, it is suggested that offprints and paged analyticals be omitted.

\section{Public Documents Published in the United States}

Since the vast mass of American government publications, including those at the federal, state and local levels, are included in the Library of Congress printed catalog, it is recommended that American government publications be omitted. Locally published documents not recorded in the $\mathrm{Li}$ brary of Congress printed catalog would naturally be requested from state libraries or state university libraries.

\section{United Nations Documents}

Since depository libraries are listed in the United Nations Documents Index and since the United Nations Library in New York City is available for special help, there seems to be little need to include publications of the United Nations or its affiliated agencies. In any event, the Library of Congress printed catalog covers most of these publications. The publications of the various governmental international organizations (e.g., the League of Nations and the Organization of American States) can be excluded on the score that the great mass of their publications can be found in the Library of Congress printed catalog.

\section{Dissertations}

Since American dissertations should be available in the institutions which granted the degree, one location in addition to the Library of Congress is always known, and they might be omitted.

\section{Other Items}

There are undoubtedly a number of other small groups which might be omitted because they are covered elsewhere or because there is slight demand for them. Typical of these might be congressional speeches which are really reprints, or hymn books which are quite numerous but in relatively small demand, and where the location of the most important collections in the country are known, or books on other subjects where there are satisfactory printed bibliographies available.

\section{Debatable Items}

The classes of material so far considered may result in some inconvenience if they are omitted, but in general it seems reasonable to suggest their omission in order to reduce the National Union Catalog to manageable proportions for editing and publication. There remain a number of classes which should be considered but where exclusion is more debatable. These include secondary school textbooks, publications of large corporate bodies, entries for certain voluminous authors, and foreign dissertations. A brief discussion of these may be profitable.

\section{American Secondary School Textbooks}

Harvard has a special collection of over 50,000 secondary school textbooks, mainly nineteenth-century American publications. 
This number could be multiplied several times over to give a reasonable estimate of the total output recorded in the Union Catalog, but with certain notable exceptions these publications are not required for scholarly research. Moreover, their listing in many cases is troublesome because of the publishing custom of listing numerous places in the imprint and of changing the sequence of these place names to suit local exigencies. For the few scholars who are interested in this material, a list of the larger collections in the country might be sufficient. Some items have special interest (e.g., the works of Lindley Murray and the McGutfey Readers), and might be included. On the other hand, foreign textbooks might be included because they will be comparatively few in number and in some cases would be more difficult to recognize as secondary school textbooks and would certainly be more difficult to find in libraries in this country.

\section{Voluminous Authors}

Harvard has some 8,000 author entries under Shakespeare. Many problems in Shakespeare bibliography would have to be faced or glossed over if all the 8,000 entries -plus the additional thousands which other libraries could add-were included. Should not such an author be excluded and left for a special bibliography to be compiled by a competent bibliographer? Perhaps a ruling could be set up so that entries with more than a thousand titles would be omitted: the principal libraries being mentioned instead as well as any published bibliographies which represent location. If this were done, the bulk of the Union Catalog could be reduced by a million entries or more.

The thousands of entries for the Bible and its parts could come under this ruling. Likewise, the publications of major American institutions with extensive publishing programs can be omitted on this score. The 3,000 entries which the Widener Library has under Harvard University are a case in point. Anyone seeking a Harvard publication could properly apply to the Harvard University Library, and the same would hold true with other universities. Appeals for University of Chicago publications could go to the University of Chicago, and so on.

\section{Foreign Dissertations}

In a class by themselves are the very numerous foreign dissertations. The Library of Congress alone has upwards of a third of a million theses from other countries, few of which are represented in its printed catalog, though all of them are listed in the National Union Catalog.

For foreign dissertations the matter to debate is whether they should be included in the published National Union Catalog or whether they should be left for a separate bibliography. Obviously, the dissertations of noted authors should be included, e.g., Bergson. The greatest question comes with the thousands of medical and legal dissertations which can be sought in obvious places: for example (apart from the Library of Congress) the Harvard Law School Library and the Armed Forces Medical Library. Note in this connection that there is a small but steady demand for foreign theses and a number of requests for them may regularly be found in the Weekly List of Unlocated Research Books. Would a good compromise be to list all non-medical and nonlegal foreign dissertations?

\section{The Publication Program}

We estimate that the number of entries would be reduced by at least a half if the suggestions just discussed are approved. It would then seem possible to envisage a successful edition of the National Union Catalog. This edition would be printed by offset from typewritten copy. It would contain brief entries designed primarily for location purposes.

Major editing problems would remain to be faced. These relate primarily to variant printings, cross references, and entries under two or more forms of heading. These editing problems should be faced realistically, just as Winifred Gregory faced the somewhat similar problems in compiling and editing the Union List of Serials. Variant printings might be ignored when there is no good reason for recognizing them as independent bibliographical entries. Cross references should to a large extent be ignored when they are obvious or when the Library of Congress printed catalog covers them. It should be noted in this connection 
that the Library of Congress printed catalog does not by any manner of means include all the references in the Library of Congress card catalogs, a precedent which might well hold for the published National Union Catalog. And for entries under a variety of forms, the editors must do their best and allowance must be made in the published work for a certain amount of inconsistency. It would be easy to spend millions of dollars in editing the catalog, but this must be avoided. A bird in the hand is worth two in the bush.

The intent of this paper is to urge the acceptance of a limited program for the publication of the National Union Catalog. In essence the publication would be complementary to the Library of Congress printed catalog, as well as to the various other accepted bibliographies. It would not be a complete and perfect bibliography, but it would be a tremendously valuable bibliographical tool, both for the location of copies and for the compilation of bibliographies of various kinds. With the proposed expansion of the Library of Congress $\mathrm{Au}$ thor Catalog into a union catalog, beginning next year, the time has come to reproduce the retrospective National Union Catalog to the best of our ability. If general agreement can be reached on this proposal, we could ask the Library of Congress to study the costs involved, to estimate the size of the subsidy, if any, that would be required, to make possible a publication at a low enough price so that the whole project would become feasible.

\section{Future Program}

\section{(Continued from page 12)}

provide readers with information on developments in the audio-visual field. A number of readers have already expressed favorable comments on this new feature. Librarians in practice can assist in improving the journal by writing and by encouraging their staff members to write. If there is any single criterion to guide writers, it is to present new ideas. Contributors should follow the basic style of the journal in presentation, footnote citations, and tabular organization. We are counting on your full cooperation.-Maurice F. Tauber, Editor.

\section{Faculty Service}

\section{(Continued from page 15)}

ject specialists, but the functions of the specialist might well be performed immediately under the office of the director, or out of a subject divisional library, or out of a departmental library. It is believed, however, that once the service is created the confidence and support necessary to its success would soon be established in sufficient degree to make the innovation successful.

Certainly the librarian convinced of the efficacy of his calling will not cringe at improving or increasing services. Let the faint-hearted but look back over the progress of the last half-century and see how far he has come already. He should note also that special libraries have always given most of the services discussed above. Indeed, the coordination of faculty services entails little more than the adaptation of certain special library practices to an academic situation.

\section{Use of TAAB}

\section{(Continued from page 18)}

which $T A A B$ service provides.

In conclusion, it might be said that the $T A A B$ method has the virtue of being cooperative, comprehensive and competitive. It is cooperative in the sense that libraries and booksellers derive mutual benefit in a new and imaginative way. Comprehensiveness is achieved by the large-scale attention given by booksellers to an individual library's wants. It is competitive because of the number of dealers involved and this tends to encourage low quoting on items desired. The method has much to recommend it. 